\title{
Quantitative analysis of S. mutans and S. sobrinus cultivated independently and adhered to polished orthodontic composite resins
}

\author{
Ulises VELAZQUEZ-ENRIQUEZ1', Rogelio Jose SCOUGALL-VILCHIS², Rosalia CONTRERAS-BULNES ${ }^{3}$, Jaime \\ FLORES-ESTRADA ${ }^{4}$, Shinsuke UEMATSU ${ }^{5}$, Ryozo YAMAGUCHI ${ }^{6}$
}

\author{
1- DDS, MDS, Orthodontist, PhD student, Health Sciences, School of Medicine, Autonomous University of State of Mexico, Toluca City, Mexico. \\ 2- DDS, MDS, PhD, Orthodontist, Department of Orthodontics, Dental Research Center, School of Dentistry, Autonomous University of State of Mexico, \\ Toluca City, Mexico. \\ 3- DDS, PhD, Dental Research Center, School of Dentistry, Autonomous University of State of Mexico, Toluca City, Mexico. \\ 4- PhD, School of Chemistry, Autonomous University of State of Mexico, Toluca City, Mexico. \\ 5- DDS, PhD, Prosthodontics Department, School of Dentistry, Asahi University, Gifu, Japan. \\ 6- PhD, Institute of Radioisotope, School of Dentistry, Asahi University, Gifu, Japan.
}

Corresponding address: Rogelio Jose Scougall-Vilchis - Department of Orthodontics, Dental Research Center, School of Dentistry, Autonomous University of State of Mexico - Francisco Carbajal Bahena 241 - Col. Morelos - Toluca City - ZC 50120 - Mexico - Phone: +52 7222124351 - E-mail: rogelio_scougall@ hotmail.com

Received: March 7, 2012 - Modification: June 22, 2012 - Accepted: July 2, 2007

\section{ABSTRACT}

Tn Orthodontics, fixed appliances placed in the oral cavity are colonized by microorganisms. Iobjective: The purpose of this study was to quantitatively determine the independent bacterial colonization of $S$. mutans and $S$. sobrinus in orthodontic composite resins. Material and methods: Seven orthodontic composite adhesives for bonding brackets were selected and classified into 14 groups; (GIm, GIs) Enlight, (GIIm, GIIs) Grengloo, (GIIIm, GIIIs) Kurasper F, (GIVm, GIVs) BeautyOrtho Bond, (GVm, GVs) Transbond CC, (GVIm,

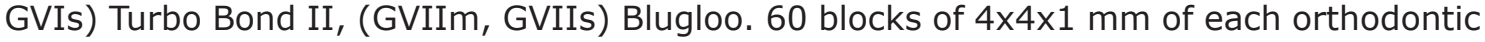
composite resin were made (total 420 blocks), and gently polished with sand-paper and ultrasonically cleaned. S. mutans and S. sobrinus were independently cultivated. For the quantitative analysis, a radioactive marker was used to codify the bacteria $\left({ }^{3} \mathrm{H}\right)$ adhered to the surface of the materials. The blocks were submerged in a solution with microorganisms previously radiolabeled and separated (210 blocks for S. mutans and 210 blocks for $S$. sobrinus) for 2 hours at $37^{\circ} \mathrm{C}$. Next, the blocks were placed in a combustion system, to capture the residues and measure the radiation. The statistical analysis was calculated with the ANOVA test (Sheffè post-hoc). Results: Significant differences of bacterial adhesion were found amongst the groups. In the GIm and GIs the significant lowest scores for both microorganisms were shown; in contrast, the values of GVII for both bacteria were significantly the highest. Conclusions: This study showed that the orthodontic composite resin evaluated in the GIm and GIs, obtained the lowest adherence of S. mutans and S. sobrinus, which may reduce the enamel demineralization and the risk of white spot lesion formation.

Key words: Radioisotope. White spot. Composite resins. Streptococcus mutans. Streptococcus sobrinus.

\section{INTRODUCTION}

The increased plaque accumulation and the concomitant bacterial acid production resulted in the white spot lesions or incipient caries. This phenomenon starts on an enamel surface when there is a shift in the equilibrium between decalcification by diffusion of the calcium and phosphate and remineralization ${ }^{10}$. The enamel demineralization is mainly caused by organic acids produced by various microorganisms. S. mutans and $S$. sobrinus were identified as the main pathogens in dental caries, and their presence increases the risk for enamel demineralization ${ }^{8,19}$. 
Therefore, adhesion of these bacteria to orthodontic composite resins or fixed appliances might influence the formation of pathogenic plaque and enamel demineralization during the orthodontic treatment ${ }^{15}$. Several patients with orthodontic treatments have a risk of developing white spot lesions around the brackets. This has been widely known from the first month after the brackets placement in ranges from $12.6 \%$ to $50 \%{ }^{14}$. Orthodontic appliances can play a major role in enamel demineralization because they provide additional surface areas for bacterial adhesion, and their complex design impedes proper access to the tooth surfaces during orthodontic treatment cleaning, furthermore, the composition of the orthodontic composite resin, the oral $\mathrm{pH}$ level and various microorganisms normally present in the oral cavity may influence the adhesion capacity of bacteria, formation of plaque, which increases the risk of demineralization in enamel, particularly in areas around the appliances such as the brackets $5,7,24$.

The orthodontic adhesives remaining on the enamel surface around the bracket are known to be risk factors for predisposition to enamel demineralization because the rough adhesive surface can provide a site for the rapid growth of oral microorganisms $9,12,22$.

The aim of this investigation was to determine and quantitatively compare the independent bacterial colonization of $S$. mutans and $S$. sobrinus in seven polished orthodontic composite resins.

\section{MATERIAL AND METHODS}

\section{Orthodontic composite resins}

Seven commercial orthodontic composite resins for bonding brackets were employed and classified in 14 groups: (GIm, GIs) Enlight (Ormco Corp., Orange, Calif., U.S.A); (GIIm, GIIs) Grengloo (Ormco Corp.); (GIIIm, GIIIs) Kurasper F (Kuraray, Medical, Tokyo, Japan); (GIVm, GIVs) BeautyOrtho Bond (Shofu, Kyoto, Japan); (GVm, GVs) Transbond CC (3M Unitek, Monrovia, Calif., U.S.A.); (GVIm, GVIs) Turbo Bond II (TP Orthodontics, LaPorte, Ind., U.S.A.); (GVIIm, GVIIs) Blugloo (Ormco Corp.).

\section{Samples preparation}

A total of 420 resin blocks (210 block for S. mutans, 210 blocks for $S$. sobrinus with 30 blocks for each group of orthodontic composite resin), were made and filled into a Teflon mold $(4 \times 4 \times 1 \mathrm{~mm})$, covered with a micro-slide glass and irradiated with a visible light curing unit device (Ortholux, 3M Unitek, Monrovia, Calif., U.S.A.) for 60 seconds to polymerize each resin block, the surface blocks were then polished with 2000 and 1000 grit sand-paper sheets, cleaned ultrasonically and sterilized with ethylene oxide gas.
Radiolabeled bacteria and culture conditions

S. mutans ATCC25165 and S. sobrinus ATCC33478 were maintained as frozen stock cultures, and cultured anaerobically at $37^{\circ} \mathrm{C}$ in a semisolid trypticase soy broth (BBL, Cockeysville, Maryland, U.S.A.) and yeast extract (Difco Laboratories, Detroit, Michigan, U.S.A.) for 18 hours. Afterwards, the microorganisms were anaerobically inoculated, each one separately from the TSBY semisolid to $150 \mathrm{ml}$ of TSBY liquid with a radioactive marker used to codify the microorganism, $74 \mathrm{kBq}$ of $\left[6^{-3} \mathrm{H}\right]$ thymidine, and cultured for 18 hours at $37^{\circ} \mathrm{C}$. Next, the bacteria was collected by centrifugation at $12000 \mathrm{rpm}$ for 15 minutes into $0.05 \mathrm{M}$ phosphate buffer saline (PBS) adjusted to $\mathrm{pH} 7.0$, and washed three times with PBS. The concentration of $S$. mutans and $S$. sobrinus were $10^{5} \mathrm{CFU} / \mathrm{ml}$.

\section{Samples analysis}

The blocks of orthodontic composite resin were suspended from the cap of a glass mold and submerged in $150 \mathrm{ml}$ of $S$. mutans (210 blocks) and $S$. sobrinus (210 blocks) radiolabeled fluid respectively at $37^{\circ} \mathrm{C}$ for 2 hours in constant movement. To remove the non-adhering bacteria, the blocks of orthodontic composite resins were removed from the glass mold and washed three times with PBS.

The radiolabeled bacteria adhered to the orthodontic composite resins blocks were recollected by automatic sample combustion equipment, and the score was measured using a liquid scintillation counter (LSC-900, Aloka, Tokyo, Japan); whose values were recorded in disintegration per minute (dpm). This measurement was repeated three times to respect the reliability of the results.

\section{Statistical analysis}

Parametric tests with descriptive mean and variance statistics for quantitative variables were used in this test by one-way analysis of variance (ANOVA) with a post hoc test (Sheffè) for multiple comparisons. A probability of equal or less than 0.05 for similarity of distribution was considered to be significantly different.

\section{RESULTS}

\section{Bacterial adhesion of $S$. mutans}

The adherence of $S$. mutans radiolabeled to orthodontic composite resins were significantly different between the groups $(p \leq 0.05)$. The scores expressed in disintegration per minute (dpm) are shown in Table 1. The value of group GIm (1577.35 $\mathrm{dpm}$ ) was significantly the lowest followed by group GIIm (3393.76 dpm). The values of group GIIm (3393.76 dpm) and GIVm (3515.56 dpm) were 
Table 1- Quantitative test to S. mutans by radiolabeled $\left({ }^{3} \mathrm{H}\right)$

\begin{tabular}{cccc}
\hline Adhesive & DPM & SD & Sheffè \\
& Mean & & Test $^{* * *}$ \\
\hline Enlight & 1577,35 & 144.57 & A \\
\hline Grengloo & 3393,76 & 113.85 & B \\
\hline Kurasper F & 3989,56 & 758.34 & $\mathrm{C}$ \\
\hline BeautyOrtho Bond & 3515,56 & 299.86 & $\mathrm{~B}$ \\
\hline Transbond CC & 4693,63 & 346.48 & $\mathrm{D}$ \\
\hline Turbo Bond & 4790,68 & 265.93 & $\mathrm{D}$ \\
\hline Blugloo & 5155,85 & 40.49 & $\mathrm{E}$ \\
\hline
\end{tabular}

* DPM (Desintegration per Minute)

** SD (Standard Deviation)

${ }^{* * *}$ Composites orthodontic resins with different letters are significantly different from each other.

Table 2- Quantitative test to $S$. sobrinus by radiolabeled $\left({ }^{3} \mathrm{H}\right)$

\begin{tabular}{cccc}
\hline Adhesive & DPM $^{*}$ & SD $^{* *}$ & Sheffè \\
& Mean & Test $^{* * *}$ \\
\hline Enlight & 457.86 & 88.35 & $\mathrm{~A}$ \\
\hline Grengloo & 1405,5 & 205.24 & $\mathrm{~B}$ \\
\hline Kurasper F & 1034,7 & 80.41 & $\mathrm{~B}$ \\
\hline BeautyOrtho Bond & 1437,21 & 200.48 & $\mathrm{~B}$ \\
\hline Transbond CC & 2056,05 & 25.95 & $\mathrm{C}$ \\
\hline Turbo Bond & 1114,95 & 88.61 & $\mathrm{~B}$ \\
\hline Blugloo & 6087,06 & 1290,64 & $\mathrm{D}$ \\
\hline
\end{tabular}

* DPM (Desintegration per Minute)

** SD (Standard Deviation)

${ }^{* * *}$ Composites orthodontic resins with different letters are significantly different from each other.

not significant. The value of group GVIIm (5155.85 $\mathrm{dpm}$ ) was significantly the highest.

\section{Bacterial adhesion of $S$, sobrinus}

The bacterial adhesion of $S$. sobrinus radiolabeled to orthodontic composite resins were also significantly different between the groups $(p \leq 0.05)$. The scores are shown in Table 2 . The value of group GIs (457.86 dpm) was significantly the lowest followed by group GIIIs (1034.70 dpm). The values of group GIIs (1405.50 dpm), GIIIs (1034.70 dpm) GIVs (1437.21 dpm) and GVIs (1114.95 dpm) were not significant between each other. The value of group GVIIs (6087.06 dpm) was significantly the highest.

\section{DISCUSSION}

White spot lesions are the first sign of enamel demineralization and this phenomena is associated to the adjacent areas around the fixed orthodontic appliances, because the orthodontic appliances provide additional surface areas for bacterial colonization; furthermore, their complex design impedes an adequate cleaning, specifically because orthodontic composite resins are materials placed onto the enamel surface that is commonly affected by demineralization (white spot lesion) and caries $^{2,5}$. Various species of bacteria are involved in the formation of the dental biofilm and white spot lesions are caused by acids produced mainly by cariogenic bacteria ${ }^{11}$. Previous studies reported that patients with orthodontic treatments normally present elevated levels of S. mutans, and S. sobrinus and this alteration in the oral flora can increase the risk of dental caries ${ }^{15,27}$, on the other hand, studies in vivo have reported that the presence of these microorganisms are also found on healthy surfaces, and its presence does not always indicate an active process of caries; however, an increased number of these microorganisms on any surface might augment the risk of developing caries lesions ${ }^{1,6}$.

The bacterial adhesion of these bacteria to orthodontic composite resins is due to electrostatic, hydrophobic interaction and van der Waals forces, 
also it has been reported that the adhesion of cariogenic streptococcus to orthodontic composite resins is higher than orthodontics appliances. This colonization might play a role in the development of cariogenic plaque and the remaining bacteria around fixed appliances can grow rapidly on tooth surfaces ${ }^{18}$. Therefore, this study was performed to specifically determine the level of $S$. mutans and $S$. sobrinus adhered on orthodontic composite resins, cultured and tested independently, because both microorganisms are considered the main reason responsible for causing dental caries, and are also the greatest producer of acid that causes enamel demineralization ${ }^{24}$.

For this investigation, the samples were not coated with saliva because previous studies ${ }^{3,4}$ had described that saliva coating did not significantly alter the adhesion patterns of $S$. mutans and $S$. sobrinus. This phenomenon is consistent with other investigations showing that saliva coating did not significantly alter the adhesion of streptococci to the underlying materials $s^{7,24}$.

The equipment and methodology used in this research, such as the automatic sample combustion machine and the liquid scintillation counter device for measuring ${ }^{3} \mathrm{H}$, had been amply described by Saku, et al. ${ }^{25}$ (2010), and Nagayama, et al. ${ }^{21}$ (2001), as well as the results expressed and recorded in disintegration per minute (dpm). In this sense, a higher value of dpm means higher radioactivity and therefore a higher adherence of a radiolabeled microorganism is found. In contrast, lower values of $\mathrm{dpm}$ indicate a lesser adherence of the radiolabeled microorganism.

The results (Tables 1 and 2) in this study showed that the groups GIm (1577.35 dpm) and GIs (457.86 dpm) had the lowest bacterial adherence and were statistically significantly different $(p \leq 0.05)$ in comparison with the other groups for both microorganisms. In the same mode, GVIIm (5155.85 dpm) and GVIIs (6087.06 dpm) had the highest bacterial adherence. In general, the level of bacterial adhesion to the materials tested was greater for $S$. mutans than for $S$. sobrinus except for GVIIs which had more affinity for $S$. sobrinus, these findings are different from other studies $^{3,4,17,18}$. A similar research by Ahn, Lim, and Lee $^{3}$ (2010), reported that in general the bacterial adhesion to orthodontic materials, particularly more to orthodontic composite resins and brackets was greater for S. mutans than for S. sobrinus, concluding that different strains have different amounts of adhesion, even though they belong to the same species. The results in this study are similar in six groups (in ranges from group GIm to GVIm, and from GIs to GVIs). However, the findings in groups GVIIm and GVIIs demonstrated that the values were greater for $S$. sobrinus than for S. mutans, which strongly suggest an affinity amongst $S$. sobrinus and the orthodontic composite resin tested in groups GVIIm and GVIIs (Blugloo).

In this study differences in the amount of the bacterial adhesion can be explained by the diverse surface characteristics of each type of orthodontic composite resin. The surface characteristics of the materials are known to influence the adhesion of bacteria to surface roughness; therefore, materials with a polished surface provide the same condition for a test bacterial colonization ${ }^{3}$. Although all the surfaces were polished, the samples of orthodontic composites resins showed different irregularities on the surfaces associated with variable bacterial adhesion. The literature suggests that the filler modifies the surface of orthodontic composite resins $^{5}$, an investigation about filler volume (wt /\%), filler size, and composition of various orthodontic composite resins demonstrated no effect on the adhesion of $S$. mutans or $S$. sobrinus ${ }^{4}$. Similar findings are comparable with Groups GIm and GIs, which presented a roughness that seemed not to be susceptible to bacterial adhesion, compared with the others groups that also had irregularities on surfaces.

The orthodontic composite resins tested in this study were light-cured; the resin evaluated in the groups: GIm and GIs presented the lowest value of dpm for both microorganisms respectively; in other words, a significantly lower quantity of S. mutans and $S$. sobrinus were adhered to this composite resin when compared with the other groups. These findings are similar with a previous study ${ }^{4}$, which evaluated the same composite resin and demonstrated the lowest bacterial adherence when tested and compared with the other materials with antimicrobial properties. Several materials for bonding brackets have antimicrobial properties; however, in previous investigations, some orthodontic composite adhesives have showed no statistically significant differences ${ }^{16-18}$.

No statistically significant differences were found in the comparison between groups GIIm and GIVm, as well as GVm and GVIm, when the $S$. mutans adherence was evaluated; in the same sense for groups GIIs, GIIIs, GIVs, GVIs no significant differences were found. Although three of the seven resins analyzed are manufactured by the same company, they have shown diverse bacterial adherence, probably due to their different compositions, filler sizes, and properties ${ }^{26}$. Further studies are warranted to analyze the biological and bacteriostatic effects of the composite resins on the adhered microorganisms. Nevertheless, the groups GVIIs and GVIIm showed the significantly highest value of $S$. mutans and $S$. sobrinus adherence, indicating a superior risk for enamel demineralization and decay. 
Previous studies ${ }^{19,22}$ in vitro models had an assay adherence of microorganisms on dental materials, reporting that the surface roughness is the main determinant of the bacterial adhesion. To minimize the effect of surface roughness on adhesion in this investigation, all surfaces were polished equally, nevertheless, in previous assessments (data not shown), in which the surfaces were untreated (not polished), the groups GIm and GIs showed the lowest bacterial adherence and GVIm, GVIs the highest adherence of microorganisms. Therefore, the polish effects seem to be irrelevant for these groups.

Based on the findings obtained in this study, it was clear that the orthodontic composite resin tested in the groups GIm and GIs, exhibited desirable properties while obtaining the lowest bacterial adhesion, this suggest to the clinic in orthodontics daily practice that the use of this composite resin might reduce the white spot lesions and caries formation during the orthodontic treatment and might also be suitable from a clinical preventive point of view. In contrast, the composite resin analyzed in the groups GVIIm and GVIIs, showed the highest adhesion; this is theoretically an unfavorable characteristic; in this context, if translated into clinical performance, this suggests that this material can be associated with an increased incidence of decalcification around fixed appliances. From a clinical point of view, it seems that various orthodontic composite resins have different levels on the adhesion of $S$. mutans and S. sobrinus. However, these data are difficult to directly apply to the clinical situation, because the materials and their characteristics are variable, according to the manufacturers. In addition, the adhesion amount of oral bacteria can be significantly influenced by the complexity of the appliances and treatment.

Despite the fact that many studies $4,13,20,23,28$ about bacterial adhesion with $S$. mutans and $S$. sobrinus exposed to different dental materials have been reported, further studies are required to evaluate and understand the mechanisms of adherence on the surface of specific orthodontic materials. After all, the study of $S$. mutans and $S$. sobrinus together and using different radio markers for codifying each bacteria, are required to accurately compare the adhesion of these microorganisms to different orthodontic composites resins.

\section{CONCLUSIONS}

This study was undertaken to analyze the level of bacterial adhesion to orthodontic composite resins. The results showed that groups GIm and GIs had the lowest quantity of $S$. mutans and $S$. sobrinus adherence respectively in an assessment carried out separately. On the other hand, the highest level of bacteria adhesion was observed in groups GVIIm and GVIIs. The outcomes suggest a significant affinity of $S$. sobrinus to adhere to group GVIIs. This research provides valuable information for identifying the orthodontic composite resin with a minor risk for developing white spot lesions and caries formation.

\section{ACKNOWLEDGES}

We would like to thank the National Council of Science and Technology in Mexico and Asahi University, Gifu, Japan for providing support in this study.

\section{REFERENCES}

1- Ahn SJ, Kho HS, Kim KK, Nahm DS. Adhesion of oral streptococci to experimental bracket pellicles from glandular saliva. Am J Orthod Dentofacial Orthop. 2003;124:198-205.

2- Ahn SJ, Kho HS, Lee SW, Nahm DS. Roles of salivary proteins in the adherence of oral streptococci to orthodontic brackets. J Dent Res. 2002;81:411-5.

3- Ahn SJ, Lim BS, Lee SJ. Surface characteristics of orthodontic adhesives and effects on streptococcal adhesion. Am J Orthod Dentofacial Orthop. 2010;137(4):489-95.

4- Ahn SJ, Lim BS, Lee YK, Nahm DS. Quantitative determination of adhesion patterns of cariogenic streptococci to various orthodontic adhesives. Angle Orthod. 2006;76(5):869-75.

5- Ahn SJ, Lim BS, Yang HC, Chang YI. Quantitative analysis of the adhesion of cariogenic streptococci to orthodontic metal brackets. Angle Orthod. 2005;75:666-71.

6- An YH, Friedman RJ. Laboratory methods for studies of bacterial adhesion. J Microbiol Methods. 1997;30:141-52.

7- Artun J, Brobakken BO. Prevalence of caries and white spots after orthodontic treatment with multibonded appliances. Eur J Orthod. 1986;8:229-34.

8- Babaahmadi KG, Challacombe SJ, Marsh PD, Newman AN. Ecological study of Streptococcus mutans, Streptococcus sobrinus and Lactobacillus spp. at sub-sites from approximal dental plaque from children. Caries Res. 1998;32:51-8.

9- Derks A, Katsaros C, Frencken JE, van't Hof MA, KuijpersJagtman AM. Caries-inhibiting effect of preventive measures during orthodontic treatment with fixed appliances. A systematic review. Caries Res. 2004;38(5):413-20.

10- Featherstone JD. The continuum of dental caries - evidence for a dynamic disease process. J Dent Res. 2004;83(Sp. Iss.):C39-42. 11- Featherstone JD. The science and practice of caries prevention. J Am Dent Assoc. 2000;131(7):887-99.

12- Fletcher M. Methods for studying adhesion and attachment to surfaces. Methods Microbiol. 1990;22(1):251-83.

13- Franco e Franco TC, Amoroso P, Marin JM, Avila FA. Detection of Streptococcus mutans and Streptococcus sobrinus in dental plaque samples from Brazilian preschool children by polymerase chain reaction. Braz Dent J. 2007;18(4):329-33.

14- Gorelick L, Geiger AM, Gwinnett AJ. Incidence of white spot formation after bonding and banding. Am J Orthod. 1982;81(2):93-8.

15- Hamada S, Slade HD. Biology, immunology, and cariogenicity of Streptococcus mutans. Microbiol Rev. 1980;44(2):331-84.

16- Korbmacher HM, Huck L, Kahl-Nieke B. Fluoride-releasing adhesive and antimicrobial self-etching primer effects on shear bond strength of orthodontic brackets. Angle Orthod. 2006;76(5):845-50. 
17- Lee SP, Lee SJ, Lim BS, Ahn SJ. Surface characteristics of orthodontic materials and their effects on adhesion of mutans streptococci. Angle Orthod. 2009;79(2):353-60.

18- Lim BS, Lee SJ, Lee JW, Ahn SJ. Quantitative analysis of adhesion of cariogenic streptococci to orthodontic raw materials. Am J Orthod Dentofacial Orthop. 2008;133(6):882-8.

19- Loesche WJ. Role of Streptococcus mutans in human dental decay. Microbiol Rev. 1986;50(4):353-80.

20- Mota SM, Enoki C, Ito IY, Elias AM, Matsumoto MA. Streptococcus mutans counts in plaque adjacent to orthodontic brackets bonded with resin-modified glass ionomer cement or resin-based composite. Braz Oral Res. 2008;22(1):55-60.

21- Nagayama M, Sato M, Yamaguchi R, Tokuda C, Takeuchi $\mathrm{H}$. Evaluation of co-aggregation among Streptococcus mitis, Fusobacterium nucleatum and Porphyromonas gingivalis. Lett Appl Microbiol. 2001;33(2):122-5.

22- Quirynen M, Marechal M, Busscher HJ, Weerkamp AH, Darius $\mathrm{PL}$, van Steenberghe $\mathrm{D}$. The influence of surface free energy and surface roughness on early plaque formation: an in vivo study in man. J Clin Periodontol. 1990;17(3):138-44.
23- Rahim ZH, Thurairajah N. Scanning electron microscopic study of Piper betle $L$. leaves extract effect against Streptococcus mutans ATCC 25175. J Appl Oral Sci. 2011;19(2):137-46.

24- Rosenbloom RG, Tinanoff N. Salivary Streptococcus mutans levels in patients before, during, and after orthodontic treatment. Am J Orthod Dentofacial Orthop. 1991;100(1):35-7.

25- Saku S, Kotake H, Scougall-Vilchis RJ, Ohashi S, Hotta M, Horiuchi S, et al. Antibacterial activity of composite resin with glass-ionomer filler particles. Dent Mater J. 2010;29(2):193-8. 26- Scougall-Vilchis RJ, Hotta Y, Hotta M, Idono T, Yamamoto $\mathrm{K}$. Examination of composite resins with electron microscopy, microhardness tester and energy dispersive $x$-ray microanalyzer. Dent Mater J. 2009;28(1):102-12.

27- Stratemann MW, Shannon IL. Control of decalcification in orthodontic patients by daily self-administered application of a water-free 0.4 per cent stannous fluoride gel. Am J Orthod. $1974 ; 66(3): 273-9$.

28- Tabchoury CP, Sousa MC, Arthur RA, Mattos-Graner RO, Del Bel Cury AA, Cury JA. Evaluation of genotypic diversity of Streptococcus mutans using distinct arbitrary primers. J Appl Oral Sci. $2008 ; 16(6): 403-7$. 